\title{
Modeling the Currency Structure of Bank Deposits: Does the Ratchet Effect Matter? ${ }^{1}$
}

\section{Introduction}

Globalization of financial markets generates possibilities for economic agents to use a whole set of instruments to hold and invest their savings. Corporations involved in international trade invest a fraction of their assets in a basket of foreign currencies to simplify international transactions and to hedge from sudden fluctuations in exchange rates. Households, small- and medium sized firms, particularly those in transitional economies, intensively diversify their savings. While making decisions on currency structure of their savings, households, as a rule, are guided by differences in real interest rates as well as by anticipated exchange rate dynamics. But diversifying their portfolio in the situations of a macroeconomic turmoil, economic agents are not guided solely by considerations of current yields - they are ready to sustain a certain shortterm loss due to a low rate of return on some parts of their portfolios for the sake of a greater robustness of the overall return on the entire investment portfolio to external shocks.

In a broader sense change in the economic agents' preferences with respect to the held set of currencies (and, as a consequence, changes in the currency structure of their savings and the currency structure of the real money supply) constitutes currency substitution ${ }^{2}$. A particular case of currency substitution is dollarization, which is the most visible phenomenon in countries with a high and/or unstable inflation and unpredictable dynamics of exchange rate movements. In such countries, as a rule, the USD and the Euro initially substitute for a domestic currency as a means of savings, and then, under a high inflation, - as a medium of exchange.

The currency structure of bank deposits depends upon both a current macroeconomic situation and the economic agents' expectations of the future dynamics and risks. That is why, once the macroeconomic situation and yield levels (interest rates) have changed, the agents' basket of currencies does not change immediately, but with a certain time delay (lag) necessary for driving a change in the agents' expectations. Such a delayed reaction by economic agents is ascribed to their anticipation of potential currency depreciation/appreciation in the future and inflation differential with the overseas economies. At the same time, economic agents tend to be more sensitive to negative shocks than to positive ones. The core of this phenomenon relates to the negative risk aversion of an overwhelming majority of economic agents.

So, in the dynamics of currency substitution one may see the phenomenon of hysteresis - the currency structure of cash/savings shows an asymmetric reaction to equivalent, albeit opposite by the sign, changes of rates of inflation, the nominal exchange and interest rates ${ }^{3}$. Besides,

\footnotetext{
${ }^{1}$ The paper is prepared on the basis of: Idrisov G., Freinkman L. Hysteresis v dinamike struktury bankovskikh vkladov: issledovaniye dlya stran SNG. M.: IEPP, Nauchnye trudy № 123, 2009

${ }^{2}$ It is worth noting that the economic literature uses the term "currency substitution" in a fairly broad sense. Depending on the context, it may mean change in the structure of cash held by economic agents, as well as in the structure of savings. The array of statistical indicators used for studying currency substitution can comprise a great number of things - from the fraction of the domestic currency to M2 in a given country to the share of bank deposits in the domestic currency in M3. See, for example, Harrison and Vymyatnina (2007), Mongardini and Mueller (1999), etc. In this paper we will avoid, wherever possible, the term "currency substitution" and will replace it with the term "substitution in the structure of bank deposits" as the most accurate definition of the effect examined in the paper.

${ }^{3}$ In economic literature, this effect is known as "ratchet effect". See, for example, Shinkevich and Oomes (2002), Mongardini and Mueller (1999), Harrison and Vymyatnina (2007), and others.
} 
changes in interest and exchange rates, and inflation may cause no immediate changes in the structure of savings. Rather, those occur with a certain time lag, which in turn depends upon the degree of macroeconomic stability.

The present paper focuses on modeling the currency structure of bank deposits that accounts for the ratchet effect. The goal of this analysis is to compare the significance of this effect in Russia's economy with that in a number of the CIS countries. In the paper, the models were built to obtain a quantitative estimation of ratchet effect for the Russian market and to assess the recent contraction of this effect relative to the post 1998 crisis period. The results of such analysis may have a practical value for conducting the monetary policy.

One of the most critical tasks we have to address is modeling of the economic agents' expectations. In this paper we use specially constructed ratchet variables as the main instrument to reflect the behavioral asymmetry in decisions made by economic agents.

\section{The Dynamics of the Currency Structure of Bank Deposits in Russia and the CIS Countries in 1995-2007}

The currency structure of bank deposits in Russia has undergone substantial changes over the decade after the 1998 crisis.

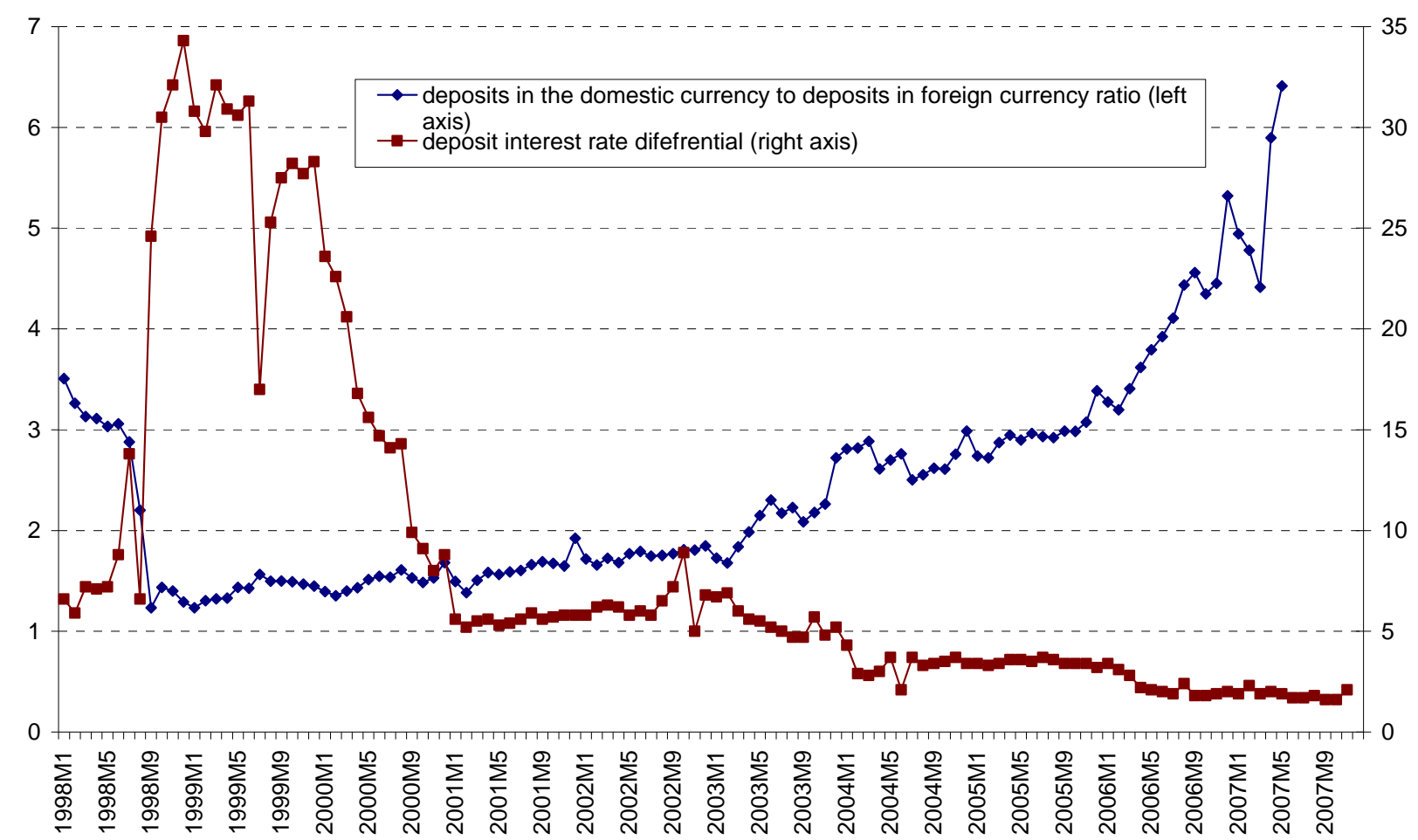

Source: the IMF data, the authors' calculations.

Fig.1. Deposits in Domestic Currency to Deposits in Foreign Exchange Ratio and the Nominal Interest Rate Differential by Deposits Denominated in the Domestic and Foreign Currencies, Russia (1998-2007).

For Russia, as well as the other CIS countries, the period in question was the time of dynamic macroeconomic changes. Fig. 1 shows the changes in deposit structure and interest rate differential, while Fig. 2 illustrates the price and the nominal exchange rate dynamics in Russia. 
Between September 1998 and December 2007 prices in Russia soared more than 6-fold, while the nominal exchange rate grew from 6 to $25 \mathrm{Rb}$. for the USD. Notably, while the inflation dynamic over the period was relatively stable, with the montly rate ranging between $0.5-2 \%$, the nominal exchange rate hit its peak of Rb. 31.84/USD in November 2002 and has been displaying the declining trend thereafter through mid-2008.

The dynamics of the Rb/USD exchange rate is driven by a great number of factors, whose detailed discussion is beyond the subject of this paper. However, for our analisys of the following fact is worth noting: in late 2002- early 2003 the earlier formed picture of relative efficiency of investments in the $\mathrm{Rb}$. and the USD underwent qualitative changes ${ }^{4}$.

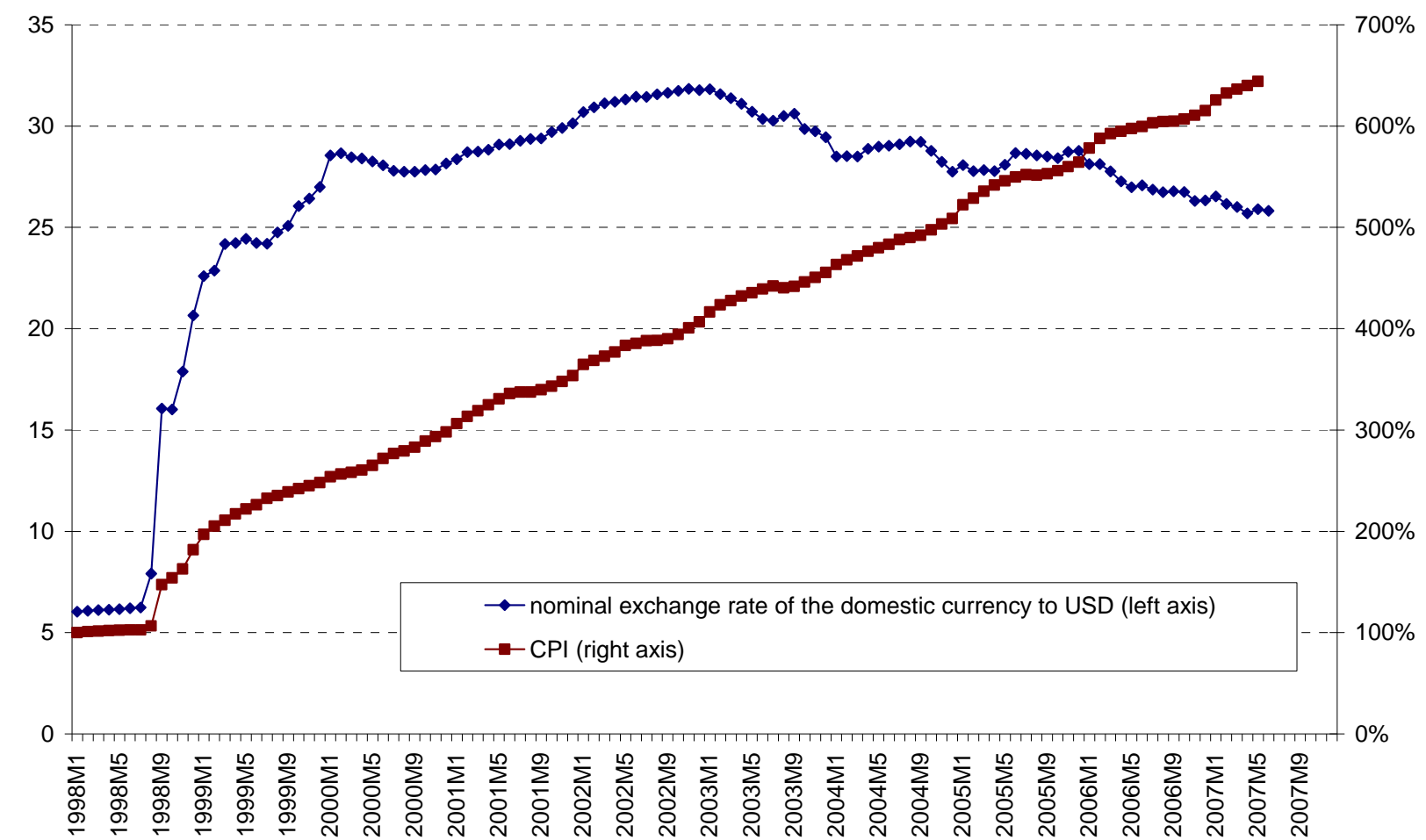

Source: the IMF data, the authors' calculations

Fig. 2. The Official Exchange Rate and the Price Level Dynamics, Russia (1998-2007)

For most CIS countries covered by the present research the early part of 2003 became the period of change in the trend in nominal exchange rate dynamics ${ }^{5}$. It was in early 2003 when among the countries that did not explicitly peg their national currencies to the USD (Russia, Kazakhstan, Armenia and Kyrgyzstan) ${ }^{6}$ three economies - namely, Russia, Kazakhstan and Armenia -- saw a reverse of the trend in the nominal exchange rate.

\footnotetext{
${ }^{4}$ In the period of the Rb. depreciation, Russian economic agents mostly got used to hold a substantial fraction of their bank savings in USD and, in addition to profit from interest on deposits, to gain on changes in market exchange rates. It was early 2003 when the economic agents' expectations began to change. The nominal appreciation of the $\mathrm{Rb}$. in 2003 fueled the population's expectations of the future appreciation of the domestic currency and formed an incentive to open new $\mathrm{Rb}$. denominated deposits or convert the earlier USD-denominated deposits into Rb.denominated ones. Thus, in the econometric part of the present paper, we will estimate our models on two separate intervals - namely, September 1998 - December 2002 and January 2003 - December 2007.

${ }^{5}$ Except for fixed pegging of their exchange rates to the USD by Belarus and Ukraine

${ }^{6}$ We do not consider Russia's soft pegging of the Rb. to the basket of currencies as a policy of fixed exchange rate regime.
} 
Fig. 3 placed below presents the dynamics of the real exchange rate of the national currencies in Russia and the other CIS countries in question ${ }^{7}$.

It is wotrth noting that the the real exchnage rate dynamics in these countries appear quite similar $^{8}$.

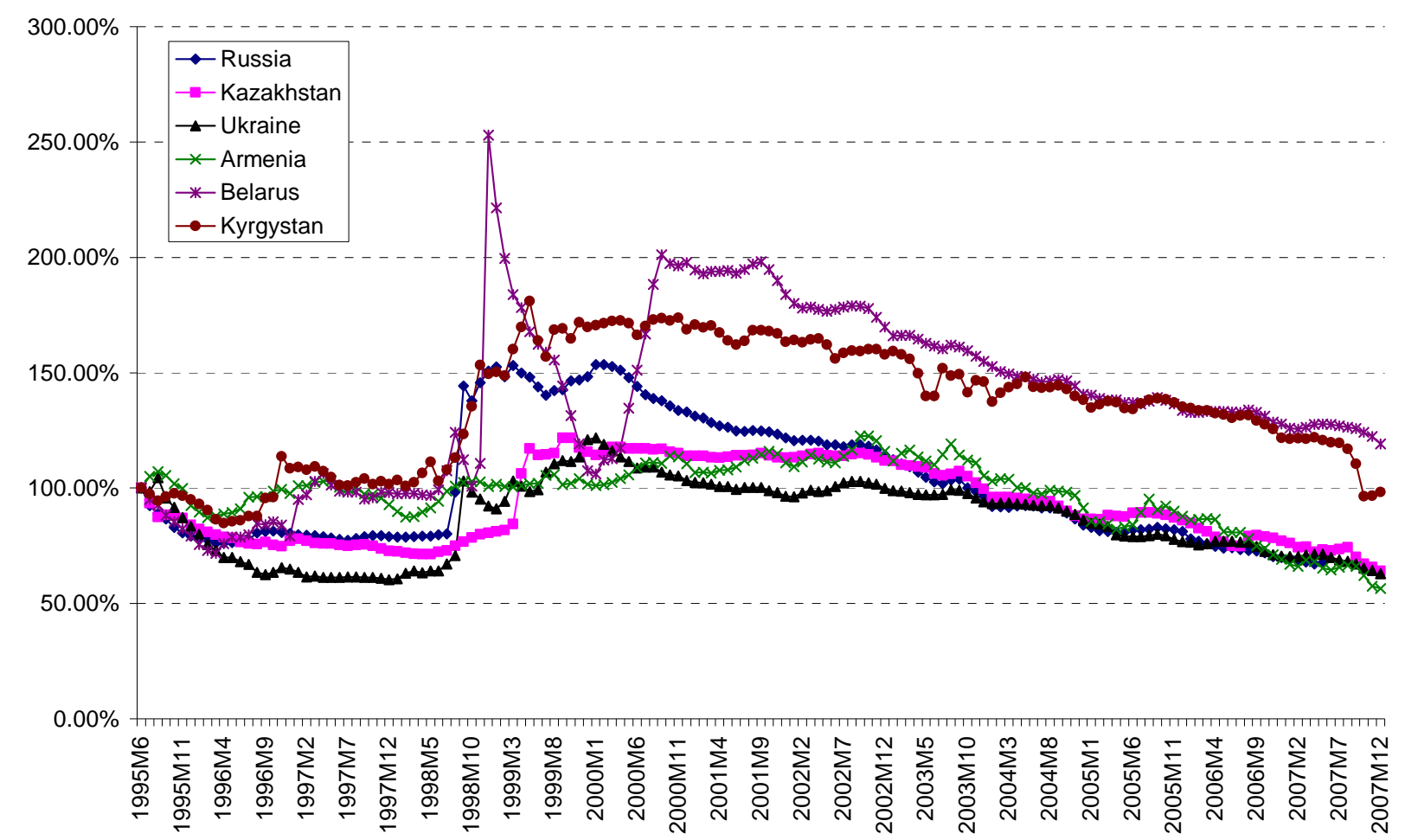

Source: the IMF data, the authors' calculations

Fig.3. Dynamics of the Real Exchange Rate in the CIS Countries (1995-2007), June 1995= $100 \%$, increase means depreciation

The comparison of the nominal exchange rates dynamics with those of the real exchange rate provides for few conclusions which will be used in the analysis below. First, while estimating the econometric models, early 2003 can be considered as a break point, as it was the time when the nominal exchnge rate dynamics in most countries in question had their trends reversed. Second, even at the first glance it is rather likely that the behavior of economic agents in one group of countries that includes Kyrgystan (due to peculiarities of its domestic nominal exchange rate dynamics), Belarus and Ukraine (due to the fixed pegging of their domestic currencies to the USD) can differ from that of economic agents in the other group of countries (Russia, Kazakhstan and Armenia) because in the period of question, macroeconomic conditions, in which economic agents made their decisions appeared substantially different between these two groups. Third, the convergence of interest rates on deposits denominated in the national currency

\footnotetext{
${ }^{7}$ In the present paper, real exchange rate is calculated as $\frac{e \cdot C P I^{*}}{C P I}$, where $e-$ nominal exchange rate [in the national currency to the USD], CPI и $C P I^{*}$ - price indices in Russia's economy and the US economy, respectively.

${ }^{8}$ Meanwhile, as demonstrated by Fig. 3, the CIS countries can be classified into two groups by the ultimate change in real exchange rate of their currencies. Russia, Kazakhstan, Armenia and Ukraine form the first group wherein by December 2007 the real exchange rate had appreciated by some 30\% vs. its respective value of June 1995 . Kyrgyzstan and Belarus form the other group, with the values of December 2007 being roughly unchanged and $20 \%$ down vs. June 1995, respectively.
} 
and on those in foreign currency indicates 1) integration of the noted economies into the global economy, and 2) decline in economic risks in the countries in question as a result of the ongoing process of macroeconomic stabilization.

\section{A Brief Review of Approaches to the Modeling of Currency Substitution}

In this section, we will briefly consider real cash protfolio balance models. For this purpose, as a rule, one employs fairly well developed analytical tools, including models that describe the structure of agents' cash holdings.

In the absence of other instruments for holding and investing, bank deposits constitute the difference between all the agents' assets and cash liquidity. That is why if we consider real cash protfolio balance models, the resulting correlations (between money supply and interest rate, exchange rate, etc.) should display opposite signs vis-à-vis those that would be expected in estimations for the deposit protfolio balance models .

\section{Currency Substitution Models}

Generally, let us note that theoretical and empirical research alike consider various indicators of currency substitution ${ }^{9}$. But provisionally all the currency substitution models can be classified into several types.

The first type is formed by two stage portfolio balance models. There at the first stage the agent makes a decision about the volumes of cash and bank deposits to hold. Stage two: for each kind of assets the agent determines their currency structure. This approach was employed, in particular, by Miles (1978). He arrived at an equation which resulted from transformation of the demand equation for the domestic and foreign money. This equation took the following form:

$$
\log \frac{M}{e M^{f}}=\alpha_{0}+\alpha_{1}\left[\log \left(1+i^{f}\right)-\log (1+i)\right]
$$

where $\frac{M}{e M^{f}}$ - relative demand for domestic and foreign currency; $i, i^{f}$ - interest rates on depoits denominated in domestic and foreign currency; $e$-nominal exchange rate.

In the frame of such an approach, coefficient $\alpha_{1}$ is considered to be the elasticity ${ }^{10}$ of currency substitution between foreign exchange and the domestic one ${ }^{11}$. Authors of models of the first type, as a rule, see one of their main goals in testing the presence of currency substitution effect, which, conceptually, is reflected in the statistical significance of coefficient $\alpha_{1}$.

\footnotetext{
${ }^{9}$ The indicators reflecting the degree of currency substitution can be estimated as the ratio of the domestic cash to all cash, the ratio of domestic currency deposits to total deposits, or the ratio of domestic currency deposits to M2. It is up to an author to opt for a particular indicator due to particular research objective and statistics at hand.

${ }^{10}$ Elasticity of relative demand to an interest rate differential.

${ }^{11}$ Empirical testing of this type models was conducted in Miles (1978), El-Erian (1988) and Mueller (1994). The subsequent improvement of the model was made by Bordo and Choudhri (1982). In Imrohoroglu's paper (1994), the author designed a stochastic intertemporal currency substitution model. Later, similar methodologies were employed by de Vries (1988), Selcuk (1997), Friedman and Verbetsky (2001). The peculiarity of this type of models is that along with currency substitution, they enable to estimate other macroeconomic effects as well. More specifically, Friedman and Verbetsky (2001) employed this approach to estimate currency substitution coefficients, seigniorage levels, and public welfare losses.
} 
Models of the second type also fall under the class of portfolio balance models. The economic agent chooses between four classes of assets: domestic and foreign currency, domestic and foreign bonds. Branson and Henderson (1985) developed the respective fundamental equation, as follows:

$$
\log \frac{M}{p}=\beta_{0}+\beta_{1} \log y+\beta_{2} r+\beta_{3}\left(r^{*}+x\right)+\beta_{4} x,
$$

where $\frac{M}{p}$ - real cash balances denominated in the domestic currency; $y$ - output of the economy; $r$ и $r^{*}$ - interest on domestic and foreign bonds, $x$ - expected depreciation of domestic currency. In the presence of the currency substitution effect coefficient $\beta_{4}$ should be negative ${ }^{12}$.

Models of the third type imply solving the consumer's classical optimization problem - utility maximization that accounts for costs of holding money (optimization models). Their main advantage and, at the same time, major difference from the above models of the first and second types is that they do not assume that the money supply is exogenous; instead it is determined within the model. The estimation of such a model was exemplified by Thomas (1985). In his model the logarithm of the domestic to foreign money ratio depends positively on interest rate for deposits in foreign currency and negatively on interest rate for domestic currency deposits.

$$
\log \frac{M}{e M^{f}}=f\left(\bar{i}, i^{f}\right) \text {. }
$$

However, the stability of interest rates (or stability of interest rate differential) on domestic and foreign currency deposits ${ }^{13}$ does not mean that the structure of money supply remains unchanged. In this case, the expected depreciation of domestic currency $(\varepsilon)$ represents alternative costs of holding cash balances in the domestic currency. That is why it should be introduced as an additional explanatory variable into equation (3):

$$
\log \frac{M}{e M^{f}}=f\left(\bar{\varepsilon}, \bar{i}_{i}^{+} i^{f}\right)
$$

In their papers, Ramirez-Rojas (1985) and Rojas-Suarez (1992) tested various specifications of equations (3) and (4) for Argentina, Mexico, Uruguay, and Peru.

In all contemporary models of currency substitution, researchers usually use fairly complex mathematical structures. These models could not be brought to a sole, convenient for econometric estimation form that would represent a relative dynamics of cash denominated in domestic and foreign currency. That is why their authors just run an empirical estimation of firstorder conditions for the economic agents' optimization problem. Models in the papers by

\footnotetext{
${ }^{12}$ This model was tested by Cuddington (1983) for Canada. The author found out that the currency substitution effect is insignificant. Other authors introduced in this model lagged values of both the explained and explanatory variables: for Mexico - Gruben and Welch (1996), for Canada - Batten and Hafer (1984), for France, Germany and UK - Marquez (1987).

In these papers, the authors interpreted significance of $\beta_{4}$ as evidence of the presence of currency substitution effect. But, while considering a special case, Cuddington (1983) demonstrated that in a portfolio model with highly developed capital markets coefficient $\beta_{4}$ can become negative and significant, regardless of whether agents are permitted to hold foreign exchange or not. That is to say the testing of the currency substitution model put forward by Branson and Henderson (1985) does not have an unequivocal interpretation. That has encouraged research of alternative models wherein the factors of demand for real cash balances were not selected exogenously.

${ }^{13}$ It can be ensured in the situation of high country integration into international trade and in absence of national barriers at the global investment market.
} 
Bufman and Leiderman (1992) and Imrohoroglu (1994) fall into this class of models. Their important peculiarity relates to the possibility to assess the dynamics of currency substitution coefficients and estimate risk aversion parameters. This allows for comprehensive studying the impact of this or that monetary policy on change in the structure of money supply.

We have reviewed the main existing approaches to estimation of the presence of currency substitution effect and determining its magnitude. The above models have both benefits and flaws. For example, models of the third type often appear complex in the course of their estimation - they are frequently presented in the form of non-linear equations or systems of equations that require testing with the number of additional assumptions and running of cuttingedge econometric methodologies. Meanwhile, estimation of currency substitution coefficients in the form of a sole equation of demand for the domestic currency (models of the second type) may suffer from inconsistency between what needs to be tested and what is actually tested. In addition models that exogenously determine the demand function for domestic or foreign currency a priori narrow the possible variations in the economic agent's choices.

\section{Estimating Currency Substitution Models in Russia}

Research into the problem of currency substitution for Russia was pioneered by Brodsky (1997). He had shown the existence of correlation between dollarization of the economy, currency depreciation and inflation. Results of those estimations were limited for two reasons - a relatively short time period (1994-1996) and a low quality of the used statistical data.

Friedman and Verbetsky (2001) tested significance of the currency substitution coefficient using foreign currency cash holdings as the currency substitution indicator. The authors found out that the elasticity of currency substitution for the period of the mid-1990s was within the range of [2$3]^{14 .}$

In their more recent paper, Oomes and Ohnsorge (2005) demonstrate the possibility to estimate aggregated money demand fuction (both for domestic and foreign currencies) by using the concept of "efficient money supply", the structure of decomposition of which into domestic and foreign components determines the degree of economy's dollarization.

Harrison and Vymyatnina (2007) modeled currency substitution effect in Russia in 1999-2005 by using several currency substitution indicators. More specifically, they exposed the presence of a steady trend to dedollarization in Russia's economy.

A more detailed review of the literature on methodology and empirical estimation of currency substitution coefficients for other countries can be found in Sharma (2005).

\section{Using Ratchet Variables in Currency Substitution Models}

Using rathcet types of explanatory variables in models aims at exposing the hysteresis effect (or, in other words, an asymmetric impact of a given factor on the dependent variable). That is to say, the dependent variable demonstrates asymmetric reaction to equivalent positive or negative changes of a particular factor. To reflect the value of the ongoing shocks, not only the fact of an assymetric influence, economists often use the maximum value of a factor (or that of the dependent variable itself) for the recent $n$ periods as ratchet variables. For example, a ratchet variable built on the basis of the variable of monthly depreciation of the nominal exchange rate $\left(e_{t}\right)$ might take the following form:

$$
\text { ratchet_e } e_{t}=\max \left\{e_{t}, e_{t-1}, \ldots, e_{t-n+1}\right\} \text {. }
$$

\footnotetext{
${ }^{14}$ With the CBR statistics used for the time interval of 1995-2000.
} 
In the event such ratchet variables appear significant in regressions, it is assumed that we deal with the hysteresis effect in the dynamic of a depended variable.

The history of application of such ratchet variables can be tracked back for decades, with one of the papers that had pioneered the area was that of Duesenberry $(1952)^{15}$.

Ratchet variables are fairly often used in estimation of money demand function ${ }^{16}$. Furthermore, researches have recently found the presence of hysteresis in foreign money demand functions ${ }^{17}$.

As well, a conceptual interpretation of ratchet variables, should they turn to be significant, plays a peculiar role. Research into hysteresis under currency substitution most often explains them based on the following considerations:

1) it takes time for economic agents to get training and get accustomed to the use of another currency (market instruments that become available with the use of alternative currency) ${ }^{18}$. This effect is usually modeled by introducing the switch costs between different kinds of currency. Under a relatively small change of, for instance, interest rates, there will be no currency substitution - the switch costs appear greater than benefits from changing the currency;

2) currency substitution requires some time for economic agents to adjust to and appreciate the fact that the ongoing macroeconomic situation is stable and the unfolded trends will not further undergo drastic changes ${ }^{19}$.

From the perspective of interpretation of significance of ratchet variables for Russia, the latter approach seems to be more adequate. For the population the switch from USD to Rb. and back is less associated with training costs than with the presence of time lags for a change and stabilization of expectations and for building some confidence in the permanent nature of the newly emerged trends.

\section{Model}

In this section, we are going to present several formal behavioral models of household optimization of their deposit currency structure. The models form the basis for conducting subsequent econometric estimations. We are going to pay a particular attention to interpretation of the models and their interconnections.

While building a behavioral model of household optimization of the deposit currency structure , one can single out several incetivizing motives. At this point, it is important to note that, resting upon different assumptions concerning agents' motives, different modelling approaches lead to the same model structure and to the same results for direction of the impact by main factors on the aggregate deposit structure.

Let us start with a simple discussion of the deposit structure formation that to a certain extent could be employed for building a formal mathematical model. While making his decision about

\footnotetext{
15 The author tested a hypothesis that the household's current consumption depends on its maximum income over the time of its existence, rather than on its current income. So, the author introduced asymmetry into consumption schedule - with the income on the rise, consumption surges, but if the income plunges, consumption does not tumble.

${ }^{16}$ See: Mongardini and Mueller (1999), section V.

${ }^{17}$ More specifically, while examining the currency substitution dynamics in Argentina, Kamin and Ericsson (1993) established significance of ratchet variables for inflation. Similarly, Peiers and Wrase (1997) established significance of ratchet variables for inflation, inflation volatility, and exchange rate volatility for Bolivia. Harrison and Vymyatnina (2007) also attempted to employ ratchet variables to examine the dedollarization process in Russia's economy, but failed to establish their significance. Perhaps, the reason for their failure was that they tried to use ratchet variables that were defined as maximum values of the variables over the whole time period prior to the one under consideration, while the variables tended to decline. Mongardini and Mueller (1999) and Mueller (1994) employed ratchet variables in a somewhat peculiar fashion (they defined them as maximum values for the depended variable itself over the whole preceding period).

${ }^{18}$ See, for example, Mueller (1994)

${ }^{19}$ See: Peiers and Wrase (1997)
} 
the currency structure of deposits, the represantative economic agent can be guided by one of the following goals:

1. Profit mazimization. At this juncture, the economic agent focuses primarily on the rate of return on depoits denominated in different types of currency;

2. Minimization of transaction costs. In the situation when some goods/services are bought solely for a certain currency (for example, for Russia - only Rb. or only USD), the economic agents find its beneficial to hold a part of their assets in deposits denominated in various currencies in order to lower costs associated with currency conversion. To exemplify goods/services that can be purchased only for the domestic exchnage, one can refer to most goods/services sold within the country; as concerns goods/services available for foreign currency only, they are sold in other countries (this is particularly of immediate interest to households that make frequent overseas trips) or the domestic real estate market wherein in many developing countries prices are nominated in a stable foreign exchange.

3. Minimization of risks. This situation appears characteristic of the case when the economic agent is in pursuit of a sole purpose of guaranteeing safety of his savings in order to secure a planned purchase or be able to buy certain services in the future. Meanwhile, depending on a desirable maturity of deposits, the agent to a lesser degree will be guided by differences in rates of return on deposits. Rather, the critical parameter will be reliability of the currency in which the deposit is denominated and guarantee of completion of the purchase, i.e. stability of the exchnage rate in the short-, medium-, and long term. In other words, the agent's primary concern is to ensure a sound diversification of his portfolio and make investments in a stable currency.

Due to the current macroeconomic situation and economic agents' risk aversion, even if each individual agent opens deposits in a sole given currency, at the aggregate level we will see a diversified structure of deposits. Furthermore, even in the situation when the agents are guided only by one of the aforemetnioned purposes, at the aggregate level, the ultimate outcome of their investments could be placement of cash in different kinds of currencies and a diversified structure of deposits.

Thus, with the first goal in his mind, that is, profit maximization, the agent is mostly guided by the rates of return on deposits in the domestic or foreign currency. But the actual ultimate purchasing power of his savings upon maturity of his deposit depends not only on the nominal rates of return (interest rate) on deposits, but it is also influenced by the uncertainty associated with an anticipated inflation and exchange rate dynamics. If the level of uncertainty is fairly high and, with some probability, it allows income equality between investment in the domestic currency and in foreign one, or if there is a high probability that the real income in either currency may vary substantially, the agent may opt for a "mixed" strategy, that is, investing in the both kinds of deposits. In this case the changes in rates of return, expectations of the inflation level and the exchange rate dynamics will affect the pattern of the agent's distribution of his deposits between currencies, i.e. to domestic to foreing currency deposit ratio. So, the actual structure of deposits is seriously affected by the economic agents' expectations about the future macroeconomic situation. Should an interest rate on either kind of deposits rise, its share in the representative household's portfolio will increase. Should there arise negative expectations, for instance, of escalation of the domestic inflation, the proportion of deposits denominated in the domestic currency will decline. 
The second and third goals under consideration also imply that currency diversification of deposits will be present at the aggregate level, with the structure of deposits also undergoing modification (the same directions of changes) with the changes either in rates of return or in the expectations.

Diversification of aggregate deposits between various kinds of currencies also follows from the CAPM-type ${ }^{20}$ basic model. If, from the household's point of view, there exists an opportunity for investing in deposits denominated in different types of currency that means that one has a few risky assets available for investment. Let us note that, despite the deposits in question are those with a risk-free interest rate, they constitute risky assets per se, as the ultimate real purchasing power of the savings appears dependent on the inflation and the exchange rate, which, from the household's point of view looks like random values. By combining deposits denominated in different currencies and applying different weights, one is able to define in a space [standard deviation, expected return] the set of assets available for the agent's choice. Maximizing on this set his utility, which is partially determined by his risk aversion, each agent will choose a portfolio that is optimal for him, i.e. an optimal combination of investment in deposits denominated in different kinds of currency, which are characterized by different level of risk (standard deviation) and rate of return (expected return). Once one more other risky assets or even risk-free ones are introduced into consideration, the presence on the aggregate level of a market portfolio diversified by currency still remains fairly probable. That is to say, we still will observe some diversified structure of deposits. Changes in this structure due to changes in rates of return appears predictable and in full consistence with the conclusions that are based upon the above considerations.

Now we present the main model of this paper, which is the basis of the econometric estimation undertaken below. The model comprises hypotheses suggested above and ideas that allow us to arrive at a concrete specification.

We will assume that the consumer's task on finding an optimal asset portfolio follows from the maximization of production function of money service. This production function in question depends on volumes of each kind of currency, which the consumer receives upon expiration of the deposits. Thus, on the one hand, the agent in a certain way maximizes the amount of cash he will receive at the time of deposit maturity, while, on the other hand, even given substantial differential in rates of return, he can prefer to hold both kinds of currency for the sake of both reducing transaction costs and convenience, which are associated with purchase of certain goods (for instance, in the event of an early closure of his deposit). All these ideas are highlighted in the money service function ${ }^{21}$ to be described below.

Beyond the framework of this model is the consumer's decision about a preferable deposit to cash ratio. Thus, our model below falls under the first class of models discussed in the above brief review of literature.

To define a production function let us consider a standard CES-function (it is used in numerous research, but usually for examination of real cash balances, into which deposits transform upon expiration of their term):

$$
\frac{M S_{t+j}}{P_{d, t+j}}=\left(\alpha_{1}\left(\frac{\left(1+i_{d}\right)^{j} D_{d}}{P_{d, t+j}}\right)^{\rho}+\alpha_{2}\left(\frac{\left(1+i_{f}\right)^{j} D_{f}}{P_{f, t+j}}\right)^{\rho}\right)^{\frac{1}{\rho}},
$$

where $j$ - term of a deposit; $M S_{t+j}$ - money services at time $t+j ; D_{d}, D_{f}$ - deposits in the domestic and foreign currency; $P_{d, t}, P_{f, t}$ - domestic and foreign price indexes at time $t ; i_{d}$, and

\footnotetext{
${ }^{20}$ Capital Asset Pricing Model, see, for example, Blume, Friend (1971).

${ }^{21}$ See, for instance, Friedman and Verbetsky (2001).
} 
$i_{f}$ - interest rates on deposits in the domestic and foreign currencies; $\alpha_{1}, \alpha_{2}$-weights that reflect a comparative efficiency with which each kind of exchange renders money service.

So, the presented production function shows how the received upon the maturity of their deposits denominated in domestic and foreign currency are directly transformed into money service. Let us define the exchange rate by the purchasing power parity as $e=P_{d} / P_{f}$. Then, from the preceding expression, after the algebraic transformation, we get:

$$
M S_{t+j}=\left(\alpha_{1}\left(\left(1+i_{d}\right)^{j} D_{d}\right)^{\rho}+\alpha_{2}\left(\left(1+i_{a}\right)^{j} D_{a} e_{t+j}\right)^{\rho}\right)^{-\frac{1}{\rho}} .
$$

Now, for the sake of simplicity of the analysis, let us assume that, while solving the problem of the portfolio structure, consumers, at the first stage, make a decision on how much money in total should be held in the form of bank deposit $D_{0}$, while, at the second stage, they decide on in what manner the money should be distributed between the domestic and foreign currency deposits.

So, we can put the budget constraint for the households at the moment of time $t$ in the following form:

$$
\frac{D_{0}}{P_{d, t}}=\frac{D_{d}}{P_{d, t}}+\frac{D_{f}}{P_{f, t}} .
$$

Rewriting this expression with the use of the introduced exchange rate, we get:

$$
D_{0}=D_{d}+e_{t} D_{f} \text {. }
$$

So, the consumer's task lies in utility maximization (money service) subject to budget constraint. Without going into much detail of solving the maximization problem, we get, from the firstorder conditions, the following expression:

$$
\log \left(\frac{D_{d}}{e D_{f}}\right)=\frac{1}{1-\rho} \log \left(\frac{\alpha_{1}}{\alpha_{2}}\right)+\frac{\rho \cdot j}{1-\rho} \log \left(\frac{1+i_{d}}{1+i_{f}}\right)-\frac{\rho}{1-\rho} \log \left(\frac{e_{t+j}}{e_{t}}\right) .
$$

The above expression demonstrates that the structure of deposits (the ratio of deposits in the domestic currency to deposits in foreign currency) is determined by: 1) economic agents' preferences; 2) difference in interest rates ${ }^{22}$ on deposits; 3 ) changes in the exchange rate.

It should be noted, however, that the introduced in such a manner exchange rate combines both expectations with regard to the dynamics of nominal exchange rate and those of the difference in inflation of the domestic vs. foreign currency. Furthermore, to explain the economic agents' expectations, one additionally needs to employ the expected rate of depreciation as a variable that reflects changes in purchasing power of each currency. Thus, the model for estimation has the following form (transformation of expression (10) by introducing coefficients $\beta_{i}$ ):

$$
\log \left(\frac{D_{d}}{e_{t} D_{f}}\right)=\beta_{0}+\beta_{1} \log \left(\frac{1+i_{d}}{1+i_{f}}\right)+\beta_{2} \log \left(E X_{t}\right)+\beta_{3} \log \left(E P_{t}\right)+\beta_{4} \log \left(R E R_{t}\right),
$$

where $E X_{t}$ - the expected at the moment of time $t$ nominal monthly depreciation of the domestic exchange rate; $E P_{t}$ - the anticipated at the moment of time $t$ monthly inflation rate in the domestic exchange vs. the inflation rate in foreign currency; $R E R_{t}$ - the real exchange rate of the domestic currency at the moment of time $t$.

We assume that the model coefficients have the following signs: $\beta_{0}, \beta_{1}>0, \beta_{2}, \beta_{3}, \beta_{4}<0$. So, the greater is the interest rate differential, the bigger the domestic to foreign deposit ratio; and the greater are expectations of a relative appreciation of the domestic currency, the bigger

\footnotetext{
${ }^{22}$ Under values of interest rates, which are not drastically different from $1, \frac{1+i_{d}}{1+i_{f}} \approx 1+i_{d}-i_{f}$.
} 
domestic to foreign deposit ratio. Meanwhile, under greater expectations of depreciation of the domestic currency and inflationary expectations, deposits denominated in the domestic currency will be relatively smaller.

To reflect the impact of the variables of expectations $\log \left(E X_{j}\right)$ and $\log \left(E P_{j}\right)$ in expression (11), we constructed special ratchet variables. Selecting exact variables for modeling agents' expectations poses a separate problem, and the procedure for its solution is described below. Let us note that construction and use of these variables essentially constitutes a central feature of the approach employed in the present paper to estimate the currency substitution effect.

\section{Construction and selection of ratchet variables}

In the present paper, to model expectations regarding the exchange rate depreciation and changes in the inflation rate we employed variables that reflect a maximum depreciation/appreciation of the domestic currency and a maximum/minimum monthly difference in inflation over $k$ recent months. These variables are responsible for economic agents' negative expectations and as such, in our view, they could be used to model hysteresis in the economic agents' behavior. For example, for agents that hold their cash in the domestic currency, a nominal depreciation constitutes a negative shock, because as the result the purchasing power of their assets declines. Meanwhile, if the agent holds his savings in foreign exchange, a negative shock will be engendered by an appreciation of the domestic currency. The effect of inflation works in a similar way. So, the below variables are responsible for negative expectations shared by certain groups of agents. Hence, the ratchet variables for our econometric model are constructed by formulas:

$$
\begin{gathered}
\breve{e}_{t}=\max \left\{0, e_{t,} e_{t-1}, \ldots, e_{t-k+1}\right\} ; \\
\delta \breve{\pi}_{t}=\max \left\{0,\left(\pi-\pi^{f}\right)_{t},\left(\pi-\pi^{f}\right)_{t-1}, \ldots,\left(\pi-\pi^{f}\right)_{t-k+1}\right\} ; \\
\hat{e}_{t}=\max \left\{0,-e_{t,}-e_{t-1}, \ldots,-e_{t-k+1}\right\} ; \\
\delta \bar{\pi}_{t}=\max \left\{0,-\left(\pi-\pi^{f}\right)_{t},-\left(\pi-\pi^{f}\right)_{t-1}, \ldots,-\left(\pi-\pi^{f}\right)_{t-k+1}\right\},
\end{gathered}
$$

where $\breve{e}_{t}$ and $\delta \breve{\pi}_{t}$ - the exchange rate and inflation rate difference ratchet variables responsible for negative expectations of economic agents that hold their savings in the domestic currency; $\hat{e}_{t}$ and $\delta \pi_{t}$ - the exchange rate and inflation rate difference ratchet variables responsible for negative expectations of economic agents that hold their savings in foreign currency; $e_{t}-$ nominal monthly depreciation of the domestic currency vs. the USD; $\pi-\pi^{f}-$ monthly inflation rate difference between the domestic and the US economy.

In the frame of this approach we will label the "depth" of the economic agents' memory $(k)$ simply as $k$-lag of a ratchet variable.

Our hypothesis is that these ratchet variables are able to explain economic agents' expectations and, accordingly, to affect their investment decisions. This proceeds from the fact that for assessing either future inflation or exchange rate dynamics, households resort to historical dynamics of these indicators they bear in memory. Meanwhile, the agent's expectations are formed primarily under the impact of the most significant earlier negative changes (negative shocks), i.e. they depend upon the values of maximum depreciation/appreciation of the domestic currency and a maximum inflation rate "stored" in the agent's memory. Due to differences in the structure of preferences among individual agents, agents with different "depths" of memory present at the market simultaneously. In this case, it is some linear combination of the lags, i.e. of the ratchet variables, that will reflect aggregate expectations for society as the whole.

So, while modeling expectations, we employ auxiliary variables defined as a maximum monthly depreciation/appreciation of the exchange rate and a maximum/minimum difference in monthly inflation rates over $k$ past months. With respect to the change in depth of the memory, or the lag of ratchet variables $(k)$ below, we will formulate separate hypotheses, which will become subject to econometric estimation. 
Use of ratchet variables in econometric models brings about two results to our research. First, employing such variables, we are able to reflect in our model the hysteresis effect in the structure of bank deposits: the structure of deposits changes in a non-symmetrical way under the influence of equivalent, albeit opposite by sign, changes in exchange rate and inflation ${ }^{23}$. Second, we can examine the "depth" of the economic agents' memory and analyze how its change correlates with periods of stability and instability of the macroeconomic situation in a given country.

At this point, it is worth specifying the conceptual interpretation of coefficients for different ratchet variables which we use below. We estimate the equation of the following form:

$$
\log \left(\frac{D_{d}}{e_{t} D_{f}}\right)=\mu_{0}+\mu_{1} \log \left(\frac{1+i_{d}}{1+i_{f}}\right)+\mu_{2} \log \left(R E R_{t}\right)+\mu_{3} \log \left(\text { asy }_{t}\right) .
$$

in which we use definitions introduced above, while $a s y_{t}$ is one of the ratchet variables determined by expressions (12)-(15). The regression coefficients in equation (16) should be interpreted as follows:

- in the event the difference between interest rates changes by $1 \%$, the ratio between deposits denominated in the domestic currency and deposits denominated in foreign currency changes by $\mu_{1 \%} \%$

- in the event the real exchange rate changes by $1 \%$, the ratio between deposits denominated in the domestic currency and deposits denominated in foreign currency changes by $\mu_{2} \%$;

- in the event negative expectations about market conditions change by $1 \%$, the ratio between deposits denominated in the domestic currency and deposits denominated in foreign currency changes by $\mu_{3 \%}$. At this point, it should be noted that there are just two motives behind a change in the negative expectations:

- negative expectations are on the rise if driven by a new large-scale negative shock which has occurred over a past period and which by its volume exceeded the ones the agent had ever witnessed before;

- negative expectations are on decline as the agent "forgets", due to the ultimate "depth" of his memory, the largest negative shock he ever witnessed before, and instead in his memory remains saved a smaller shock he has witnessed relatively recently.

Which expectations (of a maximum/minimum inflation or a maximum appreciation/depreciation of the domestic currency) are specifically considered as negative ones, should be specified in every particular case below.

\section{Estimation methodology}

On the basis of results of ADL-tests of the time series in question ${ }^{24}$ it is possible to conclude that the tested series that are included in equation (11) appear to be first-order I(1) integrated. That is why to estimate a cointegration vector we should use variables in levels. Besides ratchet variables, that are $\mathrm{I}(0)$, may be also introduced into this cointergation equation. Let us note that this feature (stationarity) is caused by the way these variables were defined, which reduces substantially their dispersion ${ }^{25}$.

\footnotetext{
${ }^{23}$ If, for example, the nominal exchange rate depreciates, it will lead to a change in the respective ratchet variable; however, if it appreciates, the ratchet variable will undergo no changes until agents "forget" the negative shock.

${ }^{24}$ For detailed results, see: Idrisov, Freinkman (2009), Annex 1.

${ }^{25}$ If a ratchet variable is constructed according to formulas (12)-(15) as a maximum among several values, the dispersion is reduced because a new observation does not follow all changes in the original variable, but may, for instance, remain constant over a long period of time.
} 
The employed estimation procedure consists of two consequent steps.

At the first step, we estimate the cointegration vector (17) between the variables in question that have order I(1). It should be noted that the structure of deposits react with some lag to both changes in interest rates and the exchange rate dynamics. That is why it is possible to use these variables with a certain lag or some lag structure that ensures a greater efficiency of estimation. We used Almon distributed lags below ${ }^{26}$.

$$
\log \left(\frac{D_{d}}{e D_{f}}\right)_{t}=\alpha_{0}+\operatorname{POLIN}\left[\log \left(\frac{1+i_{d}}{1+i_{f}}\right), n_{1}, p_{1}\right]+\operatorname{POLIN}\left[\log (R E R), n_{2}, p_{2}\right]+\varepsilon_{t},
$$

where $\frac{D_{d}}{e_{t} D_{f}}-$ domestic to foreign currency deposits ratio; $\frac{1+i_{d}}{1+i_{f}}-$ interest rate differential;

RER - real exchange rate; POLIN $[x, n, p]$ - polynomial lag structure (Almon lags) of variable

$x$, the number of lags $n$. For modeling polynomial coefficients, we employ $p$-power

polynomial, namely:

$$
\begin{gathered}
\operatorname{POLIN}[x, n, p]=\beta_{0} x_{t}+\beta_{1} x_{t-1}+\beta_{2} x_{t-2}+\ldots+\beta_{n} x_{t-n} \\
\beta_{j}=\gamma_{1}+\gamma_{2}(j-\bar{c})+\gamma_{3}(j-\bar{c})^{2}+\ldots+\gamma_{p+1}(j-\bar{c})^{p}
\end{gathered}
$$

where $\bar{c}-$ a specially introduced constant that allow avoiding some numerical problems while running tests, which, should it be introduced in a proper manner, does not affect the estimation of $\beta_{j}$.

While using Almon lags, an important question relates to the selection of parameters $n$ and $p$. In practice, the power of polynomial $p$ is put exogenously (it is influenced by the number of observations at hand), while the number of lags $(n)$ is selected to reach a minimum of the information criterion $\mathrm{AIC}$ or $\mathrm{BIC}^{27}$.

Given that the series located on the left and right sides of (17) are I(1), it is also worth examining whether the residuals are stationary (whether we have estimated a cointegration vector). To do this, we need to run a non-standard test on the presence of the unit root in a series of residuals (in this case the test critical values for residuals are biased relative to the standard ones of the ADFtest).

At the second step, we add to the built regression ratchet variables defined by formulas (12)-(15) and select which exactly ratchet variables provide for the best characteristics of the model from the perspective of the information criteria. At this point, attention should be paid to a number of things:

\section{Box 1. Some characteristics of ratchet variables and their implication for our modeling}

1. Correlation between the same ratchet variables that have different "depths" (lags) appears fairly large, which is why the variables with the lags of, for instance, 5 and 6 display quite similar behavior. Furthermore, if in one regression it is the variable with lag 5 that "performs better", while in the other it is the variable with lag 6 that does the same, we cannot assert with certainty that the agents' expectations have undergone any change because the tests on a significant difference between the models will demonstrate their indistinguishability. In order to avoid problems of this kind, we use in the model only ratchet variables with lags with the step 5 (months), as their correlation is below 0.6.

2. Similarly correlations between similarly built ratchet variables (equal lags but different nature) appear fairly large. A simultaneous use of both ratchet variables for exchange rate and inflation leads to the insignificance of coefficient for one of them. Because of this, it is a lag that differs greatly from the lag of the second ratchet variable that will display the best

\footnotetext{
${ }^{26}$ See, for instance, Greene (2000), p. 718

${ }^{27}$ W.H. Greene, Econometric Analysis, $4^{\text {th }}$ edition, 2000. Prentice Hall, Inc.: cтp. 718.
} 
performance with regard to the first variable. In order to avoid such econometric effects, we will not estimate the model that would comprise all the ratchet variables simultaneously.

We will just examine to what degree each ratchet variable is able to bring additional explanatory power to equation (17) built at the first step and which of the variables performs better.

3. The correlation between ratchet variables responsible for negative expectations of agents, who hold their savings in the domestic and foreign currency, is nearly absent, which is proved by the conducted correlation tests ${ }^{28}$. Accordingly, to get the best results, we can use variables $\breve{e}_{t}$ and $\hat{e}_{t}\left(\delta \breve{\pi}_{t}\right.$ and $\left.\delta \bar{\pi}_{t}\right)$ in the same equation.

4. Adding ratchet variables to the model would change the coefficients for the variables selected during the first step of modeling. So, it may well happen that, in combination with these new ratchet variables, there could be found some other structure of lags of nominal interest rates and exchange rate that would bring a better value of the information criterion to the model. That is why our goal is to test whether such variables responsible for the economic agents' expectations can improve the modeling of evolution of the deposit structure vis-à-vis the already built basic model that includes only interest rates and the real exchange rate variables. As a result, we abstract from the problem of finding the single best specification of the model and focus solely on significance of individual variables and improvements in the forecasting qualities of the model, which are associated with the introduction of ratchet variables.

\section{Conceptual hypotheses for econometric estimation}

As we have found earlier, due to different dynamics of the macroeconomic indicators in the sample of countries in question, they can be provisionally classified into two groups by their macroeconomic conditions in which economic agents made their decisions on deposit structure. The first group consists of Armenia, Kazakhstan and Russia. It seems that in these countries governments' interventions have not drastically changed the economic agents' incentives with regard to placement of deposits, which is evidenced by the presented above dynamics of macroeconomic indicators. In these countries exchange rate was not fixed at a certain level, nor there were any restrictions on placement of cash in these or those types of currency deposits, and there were institutional guarantees for deposit safety for any currency. Agents in the other group of countries, that is, Belarus, Kyrgyzstan and Ukraine, are likely to have faced administrative restrictions that exerted a substantial influence on their investment behavior. The macroeconomic dynamics of the indicators in these particular countries differs substantially from that of the countries of the first group.

With regard to the use of ratchet variables for modeling economic agents' expectations, we hope to obtain the following results while estimating the model on statistical data from the countries in question for different time intervals, before and after adding the ratchet variables to the model. The results depend on the group of countries in question.

\section{Box 2. Research hypothesis for estimation}

1. Coefficients before logarithms of interest rates for the countries of the first group are positive and statistically significant $(1 a)^{29}$, as with a greater difference between interest

\footnotetext{
${ }^{28}$ For detailed findings, see: Idrisov, Freinkman (2009), Annex 1.

${ }^{29}$ Below we will index hypotheses in brackets
} 
rates on deposits in different currencies, one should expect a redistribution of deposits in favor of the domestic currency. In addition, while estimating on more recent intervals (1b), we expect for these countries an increase in the absolute value of the coefficients, which can be ascribed to an increase in the households' rationality. That is to say, once the macroeconomic stability has been reached and sustained, economic agents become more sensitive to changes in the interest rates dynamics. As well, for this group of countries one should expect, for more recent intervals, a decrease in the average weighted lag that ensures the best quality of regression (1c). This is attributed to the fact that under the conditions of macroeconomic stability economic agents begin to react more promptly to changes in interest rates. For the other group of countries we hope to get statistically significant and positive coefficients with a interest rate differential (1d); however, due to the distortion in decision-making incentives in these countries ${ }^{30,}$ we assume that the structure of deposits there may react to the interest rates dynamics in a "wrong" way.

2. Coefficients before logarithms of real exchange rates for the first group of countries are negative and statistically significant (2a), i.e. expectations of greater appreciation of the domestic currency give boost to savings denominated in it. As conditions of macroeconomic stability are reached, we expect an analogous increase in the absolute value of this coefficient on more recent intervals (2b) and a fall in the average weighted lag (2c). For the second group of countries we hope to get statistically significant and positive coefficients before logarithms of exchange rates (2d); however, due to the distortions in decision-making incentives, we assume that the structure of deposits in these countries may react to the exchange rates dynamics in a "wrong" way.

3. For the countries where empirical data speaks in favor of hypotheses (1a) and (2a), it can be asserted, with a certain degree of certainty, that the model has right specification. It is only for these countries/periods we will proceed to step two of the described above econometric procedure. We expect that coefficients obtained at the step two(after adding various ratchet variables) will have a right sign (3a), namely: signs of the coefficients under the variable of logarithm $\breve{e}_{t}$ and logarithm $\delta \breve{\pi}_{t}$ would be negative, as greater expectations of depreciation of the national currency and greater expectations of domestic inflation entail the redistribution of deposits in favor of the foreign currency, hence a decrease in $\frac{D_{d}}{e D_{f}}$. The signs before logarithm $\hat{e}_{t}$ and $\delta \hat{\pi}_{t}$ are also expected to be negative, as an acceleration of the nominal appreciation of currency (decrease in ${ }^{{ }_{t}}$ ) and / increase in the difference of inflation rates between domestic and the foreign currency (decrease in $\delta \bar{\pi}_{t}$ ) results in redistribution of deposits in favor of domestic currency, i.e. in the rise in $\frac{D_{d}}{e D_{f}}$.

4. In addition, with time we expect changes in lags of the ratchet variables that result in the model's greatest predictive qualities. Under transition from the periods of general macroeconomic instability to the periods of relative stability the agents need relatively less time to adopt to a decrease in inflation /depreciation rate, which is why we expect that the "lags" of the asymmetric variables will decline with time. Meanwhile, under a growing instability - escalation of inflation or a greater rate of depreciation of the domestic currency - it would take agents more time to normalize their expectations, which is reflected by a surge in the "lags" of ratchet variables. That is to say,

\footnotetext{
${ }^{30}$ A greater governmental participation in the economy, fixing nominal exchange rates or restricting interest rates, an unstable political situation, and, as a consequence, greater uncertainty about the future distort the population's investment decisions.
} 
formulating this hypothesis for the first group of countries, we expect a fall in the "lags" of the ratchet variables for more recent intervals (4a).

\section{Estimation Results}

In this section, we present estimation results of the proposed aforementioned procedure and discuss their consistency with the set hypotheses.

The general results of the cointegration vector estimation for the CIS countries are given in Table 1. In the Table we provide estimates for the long-term effects of the difference in interest rates and exchange rate, which were calculated as the sum of all the coefficients under the respective lags, as well as their significance, and other characteristics of regressions. Let us note that we provide ultimate estimated values, i.e. we present the best values of the parameters. As noted above, the estimations were undertaken for two time intervals: September 1998 - December 2002 and January 2003 - December 2007. Accordingly, there are some 60 observations in every subperiod, i.e. while estimating equation (17) it appeared sensible ${ }^{31}$ to set $p_{1}=p_{2}=3^{32}$.

The presented results suggest that the structure of deposits indeed depends on interest rates and the real exchange rate movements. Most coefficients appear to have an envisaged sign and to be statistically significant. The sums of all the coefficients, that constitute the long-term impact on the depended variable ${ }^{33}$ by the explanatory ones, have an envisaged sign and are statistically significant. Thus, for example, the results for the second period for Russia demonstrate that a $1 \%{ }^{34}$ long-term increase in interest rates between deposits denominated in the domestic currency and those in foreign currency results in a $27.3 \%$ rise in domestic to foreign currency ratio, while a $1 \%$ depreciation of the real exchange rate will lead to a $4.0 \%$ drop in the above ratio.

\footnotetext{
${ }^{31}$ The greater the value of $p$ is, the better testing of the lag structure is; however, increasing $p$ restricts the number of degrees of freedom of the estimated regression. Thus, $p_{1}=p_{2}=3$, as the authors believe, reflects an acceptable compromise for this number of observations.

${ }^{32}$ For more details, see: Idrisov, Freinkman (2009), Annex 3.

${ }^{33}$ Proceeding from expression (18), the change of the explanatory variable at $\Delta x$ should lead to the change in the explained variable at $\sum \beta_{i}$

${ }^{34}$ The specified rate in the equation $\frac{1+i_{d}}{1+i_{f}}$, its increase at $1 \%$ is roughly equal to a 1 pct. surge in the rate by the domestic deposits, as $\frac{1+i_{d}}{1+i_{f}} \approx 1$
} 
The summary of estimates, Equation (17), before the ratchet variables

\begin{tabular}{|c|c|c|c|c|c|c|c|c|c|c|c|c|c|c|c|c|c|c|c|c|}
\hline \multicolumn{21}{|c|}{ Depended variable- the logarithm of the deposits in the domestic currency to deposit in foreign currency ratio } \\
\hline & \multicolumn{4}{|c|}{ Russia } & \multicolumn{4}{|c|}{ Kazakhstan } & \multirow{2}{*}{\multicolumn{2}{|c|}{$\begin{array}{c}\text { Armenia } \\
2^{\text {nd }} \text { period } \\
\end{array}$}} & \multicolumn{4}{|c|}{ Kyrgyzstan } & \multirow{2}{*}{\multicolumn{2}{|c|}{$\begin{array}{c}\text { Belarus } \\
2^{\text {nd }} \text { period } \\
\end{array}$}} & \multicolumn{4}{|c|}{ Ukraine } \\
\hline & \multicolumn{2}{|c|}{$1^{\text {st }}$ period } & \multicolumn{2}{|c|}{$2^{\text {nd }}$ period } & \multicolumn{2}{|c|}{$\mathbf{1}^{\text {st }}$ period } & \multicolumn{2}{|c|}{$2^{\text {nd }}$ period } & & & \multicolumn{2}{|c|}{$1^{\text {st }}$ period } & \multicolumn{2}{|c|}{$2^{\text {nd }}$ period } & & & \multicolumn{2}{|c|}{$\mathbf{1}^{\text {st }}$ period } & \multicolumn{2}{|c|}{$2^{\text {nd }}$ period } \\
\hline & Coef. & $\begin{array}{c}p- \\
\text { value }\end{array}$ & Coef. & $\begin{array}{c}p- \\
\text { value. }\end{array}$ & Coef. & $\begin{array}{c}\mathrm{p}- \\
\text { value. }\end{array}$ & Coef. & $\begin{array}{c}\mathrm{p}- \\
\text { value. }\end{array}$ & Coef. & $\begin{array}{c}\text { p- } \\
\text { value. }\end{array}$ & Coef. & $\begin{array}{c}\mathrm{p}- \\
\text { value. }\end{array}$ & Coef. & $\begin{array}{c}\mathrm{p}- \\
\text { value. }\end{array}$ & Coef. & $\begin{array}{c}\mathrm{p}- \\
\text { value. }\end{array}$ & Coef. & $\begin{array}{c}\mathrm{p}- \\
\text { value. }\end{array}$ & Coef. & $\begin{array}{c}P \text { - } \\
\text { value. }\end{array}$ \\
\hline Constant & 5.21 & 0.000 & 11.49 & 0.000 & 11.13 & 0.000 & 11.79 & 0.000 & 81.15 & 0.000 & 7.39 & 0.000 & -23.77 & 0.067 & 7.18 & 0.000 & -1.70 & 0.001 & 0.82 & 0.004 \\
\hline $\begin{array}{l}\text { The long- } \\
\text { term effect } \\
\text { (elasticity) } \\
\text { of increment } \\
\text { in the } \\
\text { interest rate } \\
\text { differential }\end{array}$ & $\begin{array}{c}0.67 \\
{[[0.16 ;} \\
1.19]\end{array}$ & 0.013 & $\begin{array}{c}27.34 \\
{[14.44} \\
40.23]\end{array}$ & 0.000 & $\begin{array}{l}11.04 \\
{[7.95 ;} \\
14.12]\end{array}$ & 0.000 & $\begin{array}{l}18.57 \\
{[8.24} \\
28.90]\end{array}$ & 0.001 & $\begin{array}{c}286.69 \\
{[217} \\
356]\end{array}$ & 0.000 & $\begin{array}{c}9.13 \\
{[6.77 ;} \\
11.50]\end{array}$ & 0.000 & $\begin{array}{c}218.14 \\
{[172} \\
263]\end{array}$ & 0.000 & $\begin{array}{c}-7.57 \\
{[-} \\
9.98 ;- \\
5.17]\end{array}$ & 0.000 & $\begin{array}{c}-4.94 \\
{[-5.85} \\
-4.03]\end{array}$ & 0.000 & $\begin{array}{c}15.97 \\
{[7.98} \\
23.97]\end{array}$ & 0.000 \\
\hline $\begin{array}{l}\text { The long- } \\
\text { term effect } \\
\text { (elasticity) } \\
\text { of } \\
\text { depreciation } \\
\text { of the } \\
\text { domestic } \\
\text { currency }\end{array}$ & $\begin{array}{c}-1.48 \\
{[-1.94} \\
-1.04]\end{array}$ & 0.000 & $\begin{array}{c}-4.04 \\
{[-4.99} \\
-3.08]\end{array}$ & 0.000 & $\begin{array}{c}-2.48 \\
{[-2.73} \\
-2.22]\end{array}$ & 0.000 & $\begin{array}{c}-2.57 \\
{[-2.93} \\
-2.21]\end{array}$ & 0.000 & $\begin{array}{c}-14.40 \\
{[-} \\
16.91 \\
-11.89]\end{array}$ & 0.000 & $\begin{array}{c}-2.52 \\
{[-3.51} \\
-1.54]\end{array}$ & 0.000 & $\begin{array}{c}5.09 \\
{[-1.78} \\
11.96]\end{array}$ & 0.153 & $\begin{array}{c}4.44 \\
{[2.34} \\
6.54]\end{array}$ & 0.000 & $\begin{array}{c}-1.34 \\
{[-1.77} \\
-0.91]\end{array}$ & 0.000 & $\begin{array}{c}0.13 \\
{[7.98} \\
23.97]\end{array}$ & 0.401 \\
\hline$R^{2}$ & \multicolumn{2}{|c|}{0.8559} & \multicolumn{2}{|c|}{0.9453} & \multicolumn{2}{|c|}{0.9338} & \multicolumn{2}{|c|}{0.9264} & \multicolumn{2}{|c|}{0.9852} & \multicolumn{2}{|c|}{0.8574} & \multicolumn{2}{|c|}{0.8691} & \multicolumn{2}{|c|}{0.9622} & \multicolumn{2}{|c|}{0.9868} & \multicolumn{2}{|c|}{0.8795} \\
\hline$R_{a d j}^{2}$ & \multicolumn{2}{|c|}{0.8285} & \multicolumn{2}{|c|}{0.9353} & \multicolumn{2}{|c|}{0.9228} & \multicolumn{2}{|c|}{0.9149} & \multicolumn{2}{|c|}{0.9829} & \multicolumn{2}{|c|}{0.8359} & \multicolumn{2}{|c|}{0.8486} & \multicolumn{2}{|c|}{0.9505} & \multicolumn{2}{|c|}{0.9833} & 0.86 & \\
\hline
\end{tabular}

Note. $1^{\text {st }}$ period: September 1998 - December 2002; $2^{\text {nd }}$ period - January 2003 - December 2007

The $95 \%$ symmetric confidence interval is given in square brackets.

Source: the authors' calculations. 
Based on the results presented in Table 1, it can be concluded that the data speak in favor of hypotheses (1a) and (2a) for the countries of the first sub-group (Armenia, Kazakhstan, Russia). In these countries, economic agents relatively efficiently respond to changes in the difference between interest rates and to exchange rate movements. In addition, we note that the absolute value of these elasticities rises at a more recent interval for Russia and Kazakhstan, i.e. concomitant with the transition to a greater macroeconomic stability in these countries was an increase in their economic agents' sensitivity to difference in interest rates and to changes in the exchange rates. So, hypotheses ( $1 b)$ and $(2 b)$ cannot be rejected, either.

Based on the calculations of the average weighted $\operatorname{lag}^{35}$ below, it can be concluded that for Russia the data do not speak in favor of hypothesis (1c), as the average weighted lag grows both for interest rates (from 6.8 for the first interval up to 9.7 for the second one) and for the exchange rate (from 0 to 3.4). But as far as the estimation of Kazakhstan data is concerned, the results speak in favor of this hypothesis, as the value of the average weighted lag plunges (from 11.6 to 2.9 for interest rates and from 5.0 to 0.9 for the exchange rate). As a reminder, in conceptual terms it means that economic agents have begun to react more promptly to changes in interest rates and the exchange rate, which is undoubtedly good news for policy makers that attempt to deliberately influence the structure of deposits.

As for the countries that fall under the second group, there can be noted cases of insignificance of some elasticities and those in which they have a significant "wrong" sign. For the latter cases - namely, Belarus (the 2nd period) and Ukraine (the 1st period) - we have not run the second step of our econometric procedure because we do not consider the final specification to be an accurate one. As for the other cases, we first make sure we have estimated the cointegration vector and, only where it has been done, we proceeded to the step two of procedure. The general results of estimation with added ratchet variables is presented in the following table ${ }^{36}$ (see Table 2).

TABLE 2

\section{The summary of results with added ratchet variables}

\begin{tabular}{|c|c|c|c|c|c|c|c|}
\hline \multicolumn{8}{|c|}{ The explained variable - the deposits in the domestic exchange to deposit in foreign exchange ratio } \\
\hline Country & & Russia & Kazakhstan & Armenia & Ukraine & Belarus & Kyrgyzstan \\
\hline \multirow{4}{*}{$\begin{array}{l}\text { Effect of the basic } \\
\text { variables* }\end{array}$} & \multirow[t]{2}{*}{ interest rates } & + & + & & - & & + \\
\hline & & + & + & + & + & - & + \\
\hline & \multirow[t]{2}{*}{ real exchange rate } & - & - & & - & & - \\
\hline & & - & - & - & 0 & + & 0 \\
\hline \multirow{4}{*}{$\begin{array}{l}\text { Effect of ratchet } \\
\text { variables* }\end{array}$} & \multirow[t]{2}{*}{ exchange rate $\breve{e}_{t}$} & - & 0 & & & & 0 \\
\hline & & - & 0 & 0 & + & & 0 \\
\hline & \multirow[t]{2}{*}{ exchange rate $\hat{e}_{t}$} & + & - & & & & 0 \\
\hline & & 0 & - & 0 & - & & 0 \\
\hline
\end{tabular}

35 The average weighted lag is calculated by the formula $\bar{\beta}=\sum n \beta_{n} / \sum \beta_{n}$, with the sum calculated by the coefficients significant at the $5 \%$ level. n- number of lag, $\beta_{n}$ - the respective coefficient

${ }^{36}$ For more details, see: Idrisov, Freinkman (2009), Annex 3. 


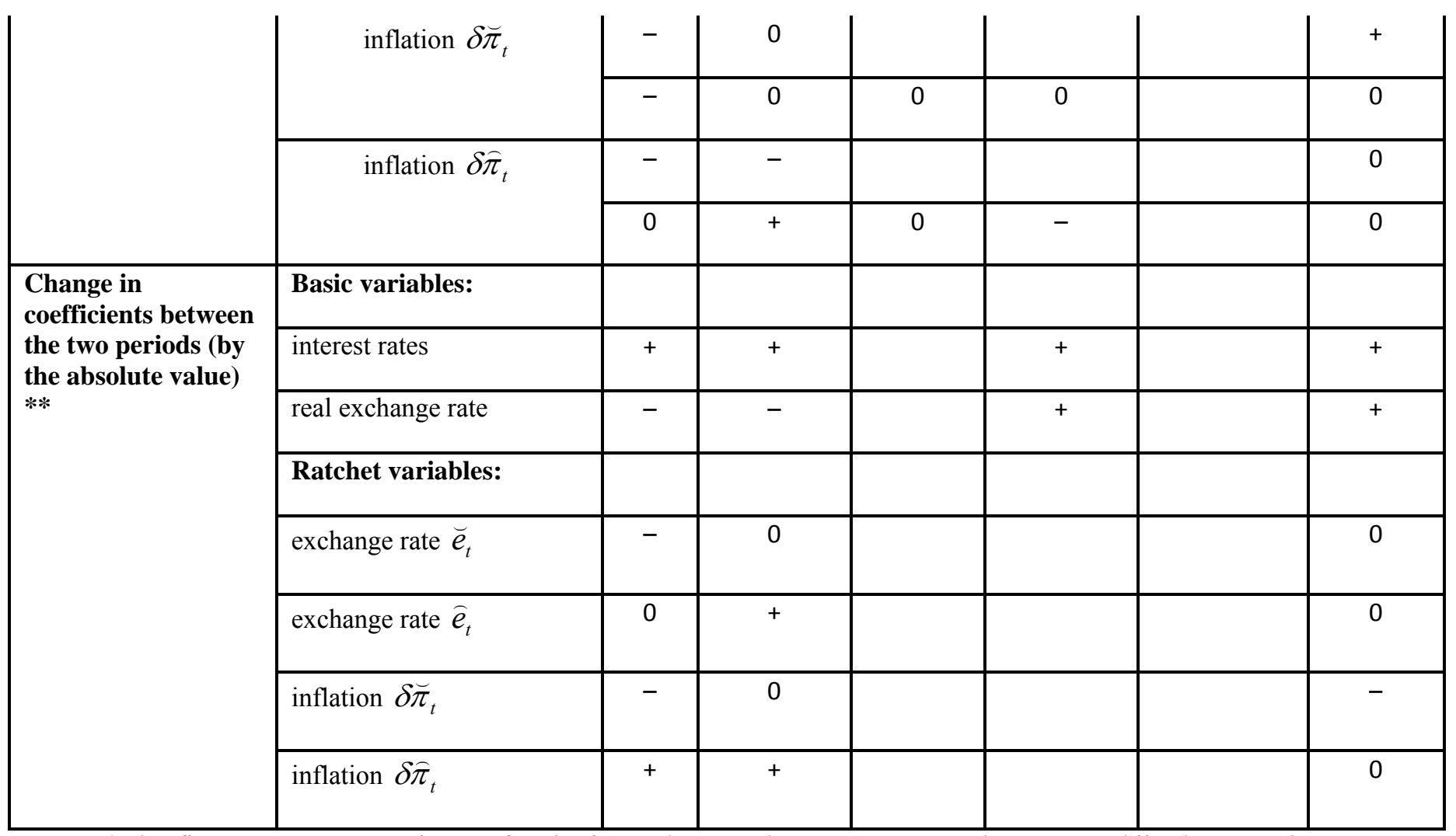

* the first row presents estimates for the interval September 1998 - December 2003, while the second one estimates for the interval January 2003 - December 2007; «+» - value of the coefficient is positive, «-» - value of the coefficient negative, «0» - insignificant, empty sell - no estimation was run.

** «+»-value increased, «-»-value reduced, «0»- changed insignificantly, empty sell - no estimation was run. Source: the authors' calculations.

When the ratchet variables are added to the model, in most cases, the coefficients, as envisaged, appear negative and statistically significant. The absolute values of the coefficients demonstrate no explicit trend to coming down to zero.

So, on the basis of our testing we can draw conceptual conclusions for the countries of the first group (Armenia, Kazakhstan, and Russia): the hysteresis effect in the dynamic of the structure of bank deposits is present in these countries for both sub-periods of estimation. This is reflected in statistical significance and the "correct" sign of the coefficients for ratchet variables. So, the data speak in favor of hypothesis (3a) for Russia and Kazakhstan. In addition, each of the countries in question displays its own peculiarities, as far as hysteresis effect is concerned (Table 3).

\section{Peculiarities of the Hysteresis Effect across the Countries of the First Group}

\begin{tabular}{|c|c|}
\hline Russia & $\begin{array}{l}\text { - Overall, for both sub-periods the ratchet variables } \breve{e}_{t} \text { and } \\
\delta \breve{\pi}_{t} \text { display a far better performance in the model than variables } \widehat{e}_{t} \\
\text { and } \delta \bar{\pi}_{t} \text {. This suggests that Russian economic agents tend to react } \\
\text { stronger to negative shocks associated with holding the domestic } \\
\text { currency }{ }^{37} \text {; } \\
\text { The impact of the ratchet variables on the structure of } \\
\text { deposits remains practically unchanged for both time intervals, i.e. }\end{array}$ \\
\hline
\end{tabular}

\footnotetext{
${ }^{37}$ Apparently this occurs even if the portfolio comprises an amount of domestic currency, which is smaller than that of foreign currency. .
} 


\begin{tabular}{|c|c|}
\hline & $\begin{array}{l}\text { hysteresis effect shows no clear trend to fading. This suggests that } \\
\text { Russian economic agents continue to be guided by their "negative" } \\
\text { memory associated with the historical dynamics of inflation and } \\
\text { exchange rate. The agents display a great deal of inertia in their } \\
\text { behavior. This is an important finding for projecting possible } \\
\text { consequences of any changes in the macroeconomic policy; } \\
\text { - The ratchet variables responsible for inflation differential } \\
\text { and the ratchet variables responsible for appreciation of the } \\
\text { exchange rate to an equal degree improve statistical characteristics } \\
\text { of the basic regression }{ }^{38} \text {. This points to the fact that Russian agents } \\
\text { appear equally sensitive to both inflation dynamic and changes in } \\
\text { the exchange rate. }\end{array}$ \\
\hline Kazakhstan & $\begin{array}{l}\text { - Ratchet variables } \hat{e}_{t} \text { and } \delta \bar{\pi}_{t} \text { perform better in regressions } \\
\text { than } \breve{e}_{t} \text { and } \delta \widetilde{\pi}_{t} \text { for both sub-periods; the situation is opposite to } \\
\text { Russia's. Negative shocks associated with holding foreign currency } \\
\text { explain the structure of deposits better than the shocks associated } \\
\text { with holding the tenge (Kazakh currency); } \\
\text { - The role played by the ratchet variables in explaining the } \\
\text { structure of deposits remains unchanged between two time intervals, } \\
\text { and the hysteresis effect shows no explicit trend to fading; } \\
\text { - Until } 2003 \text { the asymmetric variables responsible for the } \\
\text { inflation differential overall displayed a better performance than the } \\
\text { ratchet variables responsible for appreciation of the exchange rate, } \\
\text { while after 2003 they performed worse. This suggests that } \\
\text { Kazakhstan is most likely to see a certain degree of modification in } \\
\text { the domestic economic agents' behavior. Until } 2003 \text { they reacted } \\
\text { stronger to changes in the dynamics of the domestic inflation, while } \\
\text { after } 2003 \text { - to those in the exchange rate dynamics. }\end{array}$ \\
\hline Armenia & $\begin{array}{l}\text { - The effect of the ratchet variables on dynamics of the } \\
\text { structure of bank deposits appears substantially smaller than in } \\
\text { Russia and Kazakhstan (it is just one of the inflation variables that is } \\
\text { significant). Apparently, while making their investment decisions, } \\
\text { domestic economic agents in Armenia are to a lesser degree exposed } \\
\text { to the influence of negative past experiences. }\end{array}$ \\
\hline
\end{tabular}

For the countries of the second group we also estimated the model with the addition of ratchet variables to the basic regression, but we believe it makes no sense to evaluate the hysteresis dynamics in these cases. The model presented in this paper seems likely to fail to describe the behavior of economic agents in Belarus, Ukraine and Kyrgyzstan, which is evidenced by the fact that we did not get statistically significant results in the estimation of the impact of interest rates and exchange rate on the structure of deposits in our basic model. Overall, the analysis of hysteresis effect constitutes an analysis of the second-order effect relative to the basic impact of interest and exchange rates. That is why evaluation of the hysteresis effect does not appear justified without building a credible basic model.

\section{Conclusion}

\footnotetext{
38 This conclusion can be drawn on the basis of changes in the information criterion that happen after adding respective ratchet variables to the model..
} 
The present research has a practical significance, as, along with a clearer understanding of the ongoing currency substitution processes in the CIS countries, it enables one to specify the structure of factors that affect economic agents' investment decisions that, at the same time, exert influence on domestic currency demand. Thus, the models proposed above can be used for evaluation of possible effects of different macroeconomic and monetary policy options.

More specifically, the paper highlights that the available data speak in favor of the hypothesis that the interest rate differential and the exchange rate dynamics have a significant impact on the currency structure of deposits for Armenia, Kazakhstan, and Russia. It means that the countries' central banks are in possession of fairly efficient monetary and exchange policy instruments that can be employed to affect long-term trends in money demand, to accelerate the de-dollarization process, etc. Basing on these findings, one can introduce adjustments to the medium-term economic projections with regard to main money aggregates.

Meanwhile, the paper provides the estimation results for the hysteresis effect in the structure of bank deposits, which, as the paper proves, may not be ignored in the course of consideration of the economic agent's behavioral model. The agents react to changes in the macroeconomic area with a considerable lag and display different reactions to positive and negative changes in the key macroeconomic parameters. At the same time, for most countries, including Russia, there are by far no grounds to assert that the depth of the economic agents" "negative memory" has recently begun to shallow.

The main quantitative results of the paper include the following:

1) elasticity of the deposit ratio to interest and the exchange rates;

2) estimation of the impact of hysteresis effect on the structure of deposits, i.e. the scale of adjustment of the basic model to take into with account the economic agents' negative expectations.

The paper models the dynamics of the currency structure of bank deposits depending on the changes in interest rates and exchange rate dynamics in CIS countries, including Russia, between 1998 and 2007. The proposed basic model was extended by introducing the phenomenon of hysteresis (non-symmetry impact by positive and negative shocks) on the structure of deposits. As well, the authors evaluated the magnitude of the hysteresis effect in the CIS countries and its dynamics, and considered its connection with the said countries' monetary policies. The modeling of the economic agents' expectations and the phenomenon of hysteresis was conducted on the basis of designing special ratchet variables that reflect the economic agents' memory of past negative shocks.

In the empirical section of the paper, we estimated elasticities of deposit ratio to interest rate differential and exchange rate dynamics, and the magnitude of hysteresis effect in the selected CIS economies. Taking into account the general macroeconomic situation in these countries and the final results we have obtained, we suggest that economic agents in Armenia, Kazakhstan and Russia in their investment decisions have been reacting relatively efficiently to changes in interest and exchange rates. This generates additional opportunities for forecasting the impact of monetary policy in these countries. More specifically this creates favorable conditions for the national central banks to manage long-term changes in demand for money. For certain reasons (a greater government's participation in the economy, fixation of the exchange rate, limited accessibility of foreign depositary instruments) such results have not been observed yet in Belarus, Kyrgyzstan and Ukraine.

The present paper can be instrumental in development of macroeconomic and monetary policies, because its quantitative findings could be used to forecast consequences associated with various policy changes for dynamics of the structure of bank deposits in Armenia, Kazakhstan, and Russia. 


\section{References}

1. Batten D.S. and R.W. Hafer (1984). Currency Substitution: a Test of its Importance, Federal Reserve Bank of St. Louis Review 66 (7), 5-11.

2. Blume M. and I. Friend (1971). A New Look at the Capital Asset Pricing Model, Journal of Finance.

3. Bordo, Michael D. and Ehsan Choudhri (1982). Currency Substitution and the Demand for Money: Some evidence for Canada, Journal of Money, Credit and Banking (Columbus, Ohio) 14 (February), 48-57.

4. Branson, W.H. and D.W. Henderson (1985). The Specification and Influence of Assets Markets, in: R. W. Jones and P. B. Kenen, eds., Handbook of International Economics (North-Holland, Amsterdam), 749-806.

5. Brodsky, B. (1997). Dollarization and Monetary Policy in Russia, Review of Economies in Transition, Bank of Finland, vol. 6, 235-250.

6. Bufman, Gil and Leonardo Leiderman (1992). Currency Substitution under Non-expected Utility: Some Empirical Evidence, Journal of Money, Credit, and Banking 25, 320-325.

7. Calvo, G.A. and C.A. Vegh (1990). Credibility and the Dynamics of Stabilization Policy: A Basic Framework, IMF Working Paper, WP/90/110.

8. Cuddington, J. (1983). Currency Substitution, Capital Mobility and the Demand for Domestic Money, Journal of International Money and Finance 2, 111-133.

9. Duesenberry J. (1952). Income, Savings and Theory of Consumer Behavior. Cambridge, Massachusetts: Harvard University Press.

10. El-Erian M. (1988). Currency Substitution in Egypt and the Yemen Arab Republic, IMF Staff Papers 35, 85-103.

11. Feige, E.L. (2003). The Dynamics of Currency Substitution, Asset Substitution and Defacto Dollarization and Euroization in Transition Countries, Comparative Economic Studies, vol. 45, no. 3, September, 358-383.

12. Friedman, A. and A. Verbetsky (2001). Currency Substitution in Russia, Economic Education and Research Consortium Working Paper Series, Working Paper 01/05.

13. Girton, Lance and Don Roper (1981). Theory and Implications of Currency Substitution, Journal of Money, Credit and Banking 13 (February), 12-30.

14. Greene, W.H. (2000). Econometric Analysis, 4th edition, Prentice Hall, Inc.

15. Gruben W.C. and J.N. Welch (1996). Default Risk and Dollarization in Mexico, Journal of Money, Credit and Banking 28 (3), (August, Part 1), 393-401.

16. Harrison B. and Vymyatnina Y. (2007). Currency Substitution in A De-Dollarizing Economy: The Case of Russia, BOFIT Discussion Papers 3.

17. Imrohoroglu, S. (1994). GMM Estimates of Currency Substitution Between the Canadian Dollar and the U.S. Dollar, Journal of Money, Credit and Banking 26, 792-807.

18. Kamin, S. and N. Ericsson (1993). Dollarization in Argentina, International Finance Discussion Paper 460, Board of Governors of the Federal Reserve System.

19. Marquez, J.R. (1987). Money Demand in Open Economies: A Currency Substitution Model for Venezuela, Journal of International Money and Finance 6 (2), 167-178.

20. Miles, M.A. (1978). Currency Substitution, Flexible Exchange Rates, and Monetary Independence, American Economic Review 68, 428-436.

21. Mongardini, J. and Mueller, J. (1999). Ratchet Effects in Currency Substitution: An Application to the Kyrgyz Republic, IMF Working Paper, WP/99/102.

22. Mueller J. (1994). Dollarization in Lebanon, IMF Working Paper, WP/94/129.

23. Oomes, N. and Ohnsorge F. (2005). Money Demand and Inflation in Dollarized Economies: The Case of Russia, IMF Working Paper, WP/05/144.

24. Peiers, B. M. and J. M. Wrase (1997). Dollarization Hysteresis and Network Externalities: Theory and Evidence from an Informal Bolivian Credit Market, Working Paper 97-21, Federal Reserve Bank of Philadelphia. 
25. Ramirez-Rojas, C.L. (1985). Currency Substitution in Argentina, Mexico, and Uruguay, IMF Staff Papers 32, 629-667.

26. Rojas-Suarez, Liliana (1992). Currency Substitution and Inflation in Peru, Revista de Analisis Economico 7 (June), 153-176.

27. Selcuk, F. (1997). GMM Estimation of Currency Substitution in a High-Inflation Economy: Evidence from Turkey, Applied Economic Letters, No. 4, 225-227.

28. Sharma S.C., Kandil M., Chaisrisawatsuk S. (2005). Currency Substitution in Asian Countries, Journal of Asian Economics 16, 489-532.

29. Shinkevich A. and Oomes N. (2002). Dollarization Hysteresis in Russia, EERC Working Paper, January.

30. Thomas, L.R. (1985). Portfolio Theory and Currency Substitution, Journal of Money, Credit and Banking 17, 347-357.

31. Valev N. (2007). The Hysteresis of Currency Substitution: Currency Risk vs Network Externalities, Andrew Young School of Policy Studies Research Paper Series, Working Paper 07-23, April.

32. Vries, C.G. de (1988). Theory and Relevance of Currency Substitution with Case Studies for Canada and the Netherlands Antilles, Review of Economics and Statistics, vol. 70, no. 3 (Aug. 1988), 512-515.

33. Идрисов Г., Фрейнкман Л. (2009). Гистерезис в динамике структуры банковских вкладов: исследование для стран СНГ. М.: ИЭПП. Научные труды № 123Р. 